\title{
Estudo comparativo entre a técnica post mortem de Santos e a do Serviço de Inspeção Estadual para detecção de Cysticercus bovis em matadouros no Estado do Rio de Janeiro, Brasil
}

\author{
Comparative study between the Santos technique for inspection post \\ mortem, and State Inspection Service for detecting Cysticercus bovis \\ at the slaughterhouses in the State of Rio de Janeiro, Brazil
}

\author{
Robson Eduardo Vivas dos Santos, ${ }^{\star}$ lacir Francisco dos Santos, ${ }^{\star \star}$ João Campos Bonisson***
}

\begin{abstract}
Resumo
Nova metodologia de inspeção post mortem foi utilizada para a deteç̧ão de Cysticercus bovis em matadouros no Estado do Rio de Janeiro com Inspeção Estadual. O objetivo principal do trabalho foi verificar a prevalência da cisticercose bovina, aplicando técnica de inspeção post mortem, padronizada por Santos, que consistiu dos exames dos músculos mastigatórios, coração, língua e diafragma de bovinos oriundos apenas de municípios do Estado do Rio de Janeiro. Dos 430 bovinos inspecionados, 25 animais (5,81\%) tiveram cisticercos detectados com a técnica utilizada, tendo sido encontrados 14 cisticercos nos músculos mastigatórios $(3,26 \%)$, sete no coração $(1,63 \%)$, dois na língua $(0,46 \%)$ e dois no diafragma $(0,46 \%)$. A prevalência de cisticercos morfologicamente íntegros foi de $1,39 \%$ e degenerados $4,42 \%$. O estudo mostrou que a técnica de Santos de inspeção post mortem de bovinos, para a detecção de Cysticercus bovis, permitiu melhorar em $763 \%$ a eficiência na detecção desta forma larvar. Os resultados obtidos neste trabalho poderão servir de orientação e oferecer subsídios para o controle e 0 conhecimento desta zoonose no Estado do Rio de Janeiro.
\end{abstract}

Palavras-chave: estudo comparativo, técnica post mortem de Santos, Cysticercus bovis, inspeção post mortem de bovinos.

\begin{abstract}
A new methodology of post mortem inspection was used for detecting Cysticercus bovis in cattle at slaughterhouses in the State of Rio de Janeiro, under State Inspection. The main objective of this work was to verify the prevalence of Cysticercus bovis, applying techniques for post mortem inspection, standardized by Santos, that it was consisted by exams of the muscles of mastication, heart, tongue and diaphragm of bovine. Animals were originated from the State of Rio de Janeiro. Of 430 bovine inspected, 25 animals had cysticerci resulting in the prevalence of $5,81 \%$. When was applied this technique, 14 cysticerci of found were located in muscles of mastication $(3,26 \%), 07$ in the heart $(1,63 \%), 02$ in the tongue $(0,46 \%)$ and 02 in the diaphragm $(0,46 \%)$. Prevalence of morphologically intact cysticerci was 1,39 and the prevalence of degenerate ones was $4,42 \%$. The study showed that the Santos's techniques of post mortem inspection in cattle, for the detection Cysticercus bovis, allowed to improve in $763 \%$ the efficiency in the detection this larval stage, and the results obtained by this work can serve as orientation and to offer subsidies for the control and the knowledge of this zoonosis in the State of Rio de Janeiro.
\end{abstract}

Keywords: comparative study, Santos technique for post mortem inspection, Cysticercus bovis, post mortem inspection of cattle.

\section{Introdução}

A cisticercose bovina por Cysticercus bovis, estágio larvar da Taenia saginata (Goeze, 1782), é uma das principais doenças parasitárias de interesse na inspeção de carnes e na saúde coletiva.

Santos (1984) cita que os procedimentos que visam a deteç̧ão da cisticercose muscular nas carcaças de bovinos constituem uma das tarefas mais significativas para os es- pecialistas em higiene da carne e, que esta detecção durante a rotina post mortem da inspeção sanitária em matadouros é a principal baliza para prevenir a transmissão desta teníase ao homem. E afirma ainda que, embora haja dificuldade em se assegurar a ocorrência exata da cisticercose, em virtude da não-padronização dos serviços de inspeção de carnes e, a falta de registro e publicação de dados, esta zoonose é a causa mais freqüente no exame post mortem de bovinos nos estabelecimentos sob Inspeção Federal, cuja prevalência

\footnotetext{
* Médico-veterinário da Indústria Rio Branco Alimentos S.A. - Visconde do Rio Branco, MG. robsonvivas@bol.com.br

** Departamento de Tecnologia de Alimentos - Faculdade de Veterinária - Universidade Federal Fluminense. ifsantos@vm.uff.br

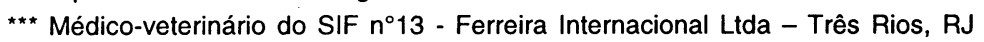


varia conforme as técnicas empregadas e as regiões de origem dos animais.

No estado de São Paulo são encontradas prevalências de cisticercose bovina, em determinados lotes, de até 100\%. A prevalência nesse estado, em estabelecimentos sob Inspeção Federal, situa-se entre 4 e $6 \%$; entretanto, municípios com ocorrência acima de $10 \%$ são muito freqüentes. Suspeita-se que nos outros estados da Federação a situação possa ser a mesma ou pior.

Pode-se considerar que esta zoonose é enzoótica e deve merecer atenção especial por parte das autoridades sanitárias do país. Sabe-se, também, que a inspeção post mortem, executada pelos diversos serviços de inspeção, apresenta variações e, em alguns casos, onde a inexistência de determinadas técnicas ou mesmo técnicas incompletas dificultam o diagnóstico desta cisticercose (Santos, 1984).

No Brasil, o consumo de carne bovina sob a forma de churrascos e bifes de grandes espessuras malpassados, que constitui hábito em certas regiões do país, bem como a preparação e o consumo de quibes crus devem ser reavaliados como fator importante na epidemiologia do complexo teníasecisticercose (Santos, 1984).

$\mathrm{Na}$ maior parte dos casos, as infecções por $C$. bovis são discretas, sua identificação se faz com certa dificuldade, mesmo naquelas regiões reconhecidas como locais de predileção, como por exemplo: músculos masseteres, pterigóideos, da língua, do coração e do diafragma (Santos, 1976).

Um dos principais problemas, em vários países, é a matança clandestina de animais. Este tipo de abate tem impedido qualquer controle sanitário sobre a carne e sua comercialização coloca em risco a saúde dos consumidores (Ungar, 1990).

Além disso, devemos lembrar que os prejuízos causados pela cisticercose para os produtores e frigoríficos, tais como: condenação de carcaças, deságio no preço do bovino, recusa de compra de animais em propriedades infectadas, seqüestro de carcaças para tratamentos, calor, frio, ou salga, custos adicionais e diminuição do valor da carcaça pela quebra do peso no congelamento (Boletim, 2001).

Dessa forma, podemos notar que uma das atividades preventivas, e de grande importância, para afastar do mercado carnes impróprias para o consumo, ou que possam ser potencialmente prejudiciais, é a inspeção sanitária criteriosa de carnes realizada em estabelecimentos caracterizados como matadouros.

Considerando estas premissas, objetivou-se com este estudo oferecer subsídios para a implantação de uma nova metodologia para a inspeção post mortem que apresente melhor eficiência na pesquisa da cisticercose bovina e que possa ser utilizada pelo Serviço de Inspeção do Estado do Rio de Janeiro.

Santos (1984) cita que a despeito da natureza polêmica da distribuição dos cisticercos no animal parasitado e da inabilidade da inspeção de rotina de carnes, os métodos de inspeção no mundo parecem ter sido influenciados pelos estudos relativos aos "locais de predileção". O exame post mortem minucioso, para a detecção da parasitose em matadouros é, sem dúvida, o meio prático exeqüível aceito para o controle eficiente da cisticercose bovina. Metodologia aperfeiçoada, inspetores de carne devidamente treinados e conscienciosos, uma iluminação adequada podem revelar uma percentagem muito maior de casos positivos.

As técnicas de exame post mortem e os procedimentos que são utilizados na inspeção de carnes demonstram variações nos diversos países. Nos Estados Unidos da América, o Manual de procedimentos de inspeção de carnes prescreve o exame dos pilares diafragmáticos e, encontrando cisticercos, deverão ser fatiados os músculos interno e externo da mastigação, o coração, o diafragma e os seus pilares.

De acordo com o artigo 176 do parágrafo $5^{\circ}$ do R.I.I.S.P.O.A. (1952), a rotina de inspeção para a detecção de cisticercos obedece às seguintes normas: cabeça - observam-se e incisam-se os masseteres e pterigóideos internos e externos; língua - o órgão deve ser observado externamente, palpado e praticados cortes quando surgir suspeita quanto à existência de cistos ou quando encontrados cistos nos músculos da cabeça; coração - examina-se a superfície externa do coração e faz-se uma incisão longitudinal, da base à ponta, através da parede do ventrículo esquerdo e do septo interventricular, examinando-se as superfícies de cortes, bem como as superfícies mais internas dos ventrículos. A seguir praticam-se largas incisões em toda a musculatura do órgão, tão numerosas quanto possível, desde que já tenha sido verificada a presença de $C$. bovis na cabeça ou na língua; inspeção final - na inspeção final identifica-se a lesão parasitária inicialmente observada e examina-se sistematicamente os músculos mastigatórios, coração, porção muscular do diafragma, inclusive seus pilares, bem como os músculos do pescoço, estendendo-se os exames aos intercostais e a outros músculos, sempre que necessário, devendo-se evitar tanto quanto possível cortes desnecessários que possam acarretar maior depreciação à carcaça.

Arundel (1972) afirma que a técnica de inspeção, para detecção do $C$. bovis, indica a incisão dos músculos masseteres (incluindo os internos), e o coração, enquanto diafragma e língua são inspecionados apenas visualmente, podendo, depois, ser fatiados, na evidência de infecção.

Porém, existem novas técnicas que aumentam a eficiência da detecção de cisticercos. Santos (1976) implantou técnica de inspeção do coração em bovinos, melhorando em $257,14 \%$ a eficiência do método em relação aos métodos convencionais e não padronizados. Santos (1984) com nova técnica de exame do diafragma no exame post mortem em bovinos, aumentou a eficiência em animais monocisticercósicos em $3,12 \%$. Santos (1993a) implantou técnica de exame dos pilares diafragmáticos, aumentando a eficiência de detecção em $4,62 \%$ para carcaças monocisticercósicas, e sugeriu um modelo de inspeção para detecção da cisticercose muscular bovina em matadouros, com base na importância dos locais de predileção em ordem decrescente de importância: coração, músculos mastigatórios, pilares diafragmáticos, esôfago, diafragma e língua.

Rodrigues (1992) conclui que a presença de um único cisticerco calcificado no conjunto de órgãos, vísceras e carcaças na rotina de inspeção, não isenta a carcaça da presença de cisticercos morfologicamente íntegros em local que não seja rotineiramente examinado. Dessa forma, ao fatiar músculos não rotineiramente inspecionados, sugere que carcaças de animais que, na linha de rotina de inspeção, tenham 
acusado a presença de, pelo menos, um único cisticerco calcificado no conjunto de órgãos, vísceras ou na carcaça, não devem ser liberadas para o consumo sem prévio tratamento pelo frio, salga ou calor.

Fukuda et al. (1998), comparando o Método Reinspeção, segundo técnica sugerida por Santos (exame do diafragma na mesa), com o Método Carcaça (exame do diafragma na carcaça) obtiveram uma eficiência de $1.449,38 \%$; citam os autores, ainda, que no Brasil não existem procedimentos padronizados oficialmente para a realização do exame do diafragma de forma rotineira nas linhas de inspeção.

\section{Material e métodos}

\section{Origem do material estudado}

O material utilizado para a realização do estudo foi obtido de 430 bovinos abatidos e inspecionados com técnicas de exame post mortem padronizadas, com idade média entre dois e quatro anos, de ambos os sexos, abatidos em matadouros sob Inspeção Estadual do Rio de Janeiro, nas cidades de Três Rios e Cantagalo. Todos os bovinos foram oriundos apenas de municípios do Estado do Rio de Janeiro, com a intenção de estabelecer um levantamento da ocorrência da zoonose no estado.

Os dados foram obtidos de quatro abates: três abates em Três Rios, nas respectivas datas e número de animais inspecionados: 12/5/2001 (160 bovinos), 9/6/2001(150 bovinos), 30/6/2001 (75 bovinos), além de um abate realizado em Cantagalo dia 10/12//2001, com 45 bovinos inspecionados.

\section{Métodos}

\section{- Exame dos músculos mastigatórios}

Os masseteres externos e internos foram incisados sagitalmente, com dois cortes dos dois lados, para cada grupo de músculo, sendo também cortados sagitalmente os pterigóideos; as incisões foram extensas e profundas, de modo a oferecerem o máximo de superfície à exploração para a detecção da cisticercose.

Foi praticado mais um corte em cada pterigóideo, totalizando dois cortes efetuados nesses músculos de cada lado, com a mesma finalidade de maior exploração.

\section{- Exame da língua}

As línguas, massas musculares e os tecidos adjacentes foram examinados visualmente, bem como foram feitos os exames táteis dos órgãos (palpação).

Foram praticados, adicionalmente, cortes na superfície ventral da língua, interessando, principalmente, os músculos extrínsecos e intrínsecos, junto à sua raiz, com a finalidade de se pesquisar cisticercos, preservando sempre a língua do ponto de vista comercial.

\section{- Exame do coração}

Foi executado conforme técnica descrita por Santos (1976): a) inspeciona-se visualmente, verificando o estado do saco pericárdico;

b) incisa-se o saco pericárdico e expõe-se o órgão;

c) destaca-se o coração dos pulmões seccionando-se em sua base, os seguintes vasos: aorta, artéria pulmonar, veia cava cranial, veias pulmonares, veia cava caudal;

d) expõe-se a cavidade átrio-ventricular direita, através de um corte que segue uma linha paralela ao sulco longitudinal, a mais ou menos $2 \mathrm{~cm}$ à esquerda deste;

e) prossegue-se com este corte para o interior da cavidade ventricular incisando a crista supra-ventricular e, mais para baixo, a cinta moderadora, atingindo a parede do ventrículo esquerdo, procurando expor a maior área possível;

f) vira-se o coração apoiando a parte incisada sobre a mesa e, pratica-se outro corte longitudinal que se inicia no átrio esquerdo, dividindo-se ao meio e seguindo até próximo ao vértice do coração, expondo as cavidades atrial e ventricular esquerdas;

g) cortam-se as cordas tendíneas próximas às suas inserções nos músculos papilares. Isto se faz necessário para a visualização de maior superfície interna, sob às cúspides das válvulas cardíacas, facilitando, desse modo, o desprendimento dos coágulos sangüíneos;

h) desdobra-se a parede do ventrículo esquerdo, à esquerda do corte inicial executado, para a abertura do ventrículo, por intermédio de uma incisão longitudinal em sua espessura, com a maior profundidade possível, atingindo, inclusive, o septo intraventricular;

i) lava-se abundantemente o coração para remover todo o sangue e para permitir uma boa visualização do endocárdio;

j) verifica-se atentamente todas as superfícies dos cortes e do endocárdio visando a possível presença de cisticercos.

\section{- Exame do diafragma}

Foi executado conforme técnica descrita por Santos (1987):

\section{Fase preparatória}

Durante a evisceração torácica, o diafragma é retirado praticando-se um corte semi-circular ao nível de sua implantação, da região renal à cartilagem xifóide. Um funcionário prende 0 diafragma em um gancho de material inoxidável e, por arrancamento e com o auxílio de uma faca, a pleura parietal e o peritônio são retirados, deixando livre, para o exame, a porção muscular.

\section{Fase de exame}

O inspetor toma a porção muscular do diafragma entre os dedos e faz deslizar, mantendo-o sob pressão, de uma extremidade à outra, palpando e observando atentamente uma das faces. Ao chegar na outra extremidade, faz a inversão da peça e repete a operação para a visualização e palpação da face oposta.

Após a detecção macroscópica das lesões, os materiais foram fixados em formol a $10 \%$ e enviados ao laboratório do 
Setor de Patologia Veterinária Prof. J. A. Santos da Universidade Federal Fluminense. Posteriormente, foram processados pelas técnicas habituais para inclusão em parafina e corados pela hematoxilina e eosina.

\section{Análise da eficiência das técnicas}

Para se calcular a eficiência das técnicas padronizadas utilizou-se a seguinte fórmula: ETP=(MPTP-MPSIE)/MPSIE X 100, sendo MPSIE a média da prevalência obtida pelo SIE (Serviço de Inspeção Estadual), no matadouro de Três Rios e MPTP a média da prevalência obtida com as técnicas padronizadas, no mesmo matadouro.

\section{Resultados e discussão}

Observa-se na Tabela 1 que dos 430 bovinos abatidos e inspecionados, 25 animais apresentaram cisticercos, correspondendo a uma prevalência de $5,81 \%$.

Considerando apenas o número de animais infectados, registraram-se as seguintes prevalências dos cisticercos nos seguintes locais: $56 \%$ nos músculos mastigatórios, $28 \%$ no coração, $8 \%$ na língua, e $8 \%$ no diafragma.

Tabela 1 - Locais onde foram encontrados Cysticercus bovis em bovinos no Estado do Rio de Janeiro

\begin{tabular}{|c|c|c|c|}
\hline \multirow[b]{2}{*}{ Locais } & \multirow[b]{2}{*}{$\begin{array}{l}\text { Número de } \\
\text { C. bovis }\end{array}$} & \multicolumn{2}{|c|}{ Prevalência } \\
\hline & & $\begin{array}{c}\text { (animais } \\
\text { abatidos) } \\
\% \\
\end{array}$ & $\begin{array}{c}\text { (animais } \\
\text { infectados) } \\
\%\end{array}$ \\
\hline $\begin{array}{c}\text { Músculos } \\
\text { mastigatórios }\end{array}$ & 14 & 3,26 & 56 \\
\hline Coração & 7 & 1,63 & 28 \\
\hline Língua & 2 & 0,46 & 8 \\
\hline Diafragma & 2 & 0,46 & 8 \\
\hline TOTAL & 25 & 5,81 & 100 \\
\hline
\end{tabular}

As prevalências de cisticercose bovina, publicadas por Costa et al. (1977) 5,32\%, e Ungar (1990) 5,46\%, são as mais próximas da prevalência obtida neste estudo $-5,81 \%$.

A prevalência de $5,81 \%$ obtida pelo exame post mortem com técnicas padronizadas supera as prevalências da cisticercose bovina no Brasil observadas por: Busetti et al. (1976) variando de $0,03 \%$ a 1,89\%; Oliveira et al. (1984) 0,74\%; Calil (1984) variando de $3,86 \%$ a $4,18 \%$; Jordão (1984) $3,62 \%$; Santos (1993) 3,79\%; Fukuda (1996) 3,74\% e Moreira (2000) $4,3 \%$.

A prevalência obtida neste estudo também foi superior às observadas em bovinos abatidos no Estado do Rio de Janeiro por Silva (1943), que registrou uma prevalência de 0,57\%; por Francis et al. (1979) que registraram uma prevalência de $0,20 \%$ em Nilópolis, $0,12 \%$ em Duque de Caxias, nenhum caso em Nova Friburgo e $0,02 \%$ em Itaboraí; e, por Teixeira (1996) que, levantando dados do Serviço de Inspeção Federal sobre a freqüência de cisticercose em bovinos provenientes de sete regiões do estado do Rio de Janeiro, abatidos em matadouro-frigorífico com inspeção federal, registrou a prevalência de 4,36\% (151 animais com cisticercose).

Os dados supracitados indicam as diferentes prevalências registradas no Brasil e no Estado do Rio de Janeiro e servem de alerta para ocorrências muito baixas de cisticercose bovina que têm sido publicadas. Fatores tais como: a região de procedência dos bovinos, número de animais estudados são causas desta distinção, porém a não padronização da técnica de inspeção post mortem, ou mesmo a sua inexistência, tornam-se o motivo principal dos desencontros de dados.

Os dados obtidos com este estudo são semelhantes àqueles apresentados por Koudela (1966), Drabble (1969) e Gibson (1969) apud Santos (1984), que reconhecem como locais de predileção para a detecção da cisticercose bovina os músculos mastigatórios, o coração, a língua e o diafragma.

A maioria dos autores cita como principais locais de predileção os músculos mastigatórios e o coração. Entretanto, existem diferentes opiniões sobre em que local a prevalência é maior.

A prevalência de $3,26 \%$ nos músculos mastigatórios ( 14 cisticercos) demonstra que, neste estudo, este foi o principal local de predileção dos cisticercos, concordando com trabaIhos de Pardi et al. (1952), Koudela (1966) e Mc Cool (1979), que verificaram como principal sítio de localização dos $C$. bovis os músculos mastigatórios.

Dos 14 cisticercos detectados nos músculos mastigatórios ( $56 \%$ da prevalência total), $55 \%$ estavam nos masseteres e $45 \%$ no pterigóideos. Dessa forma, concorda-se com o procedimento descrito no Manual de Procedimentos de Inspeção de Carnes dos Estados Unidos da América ("The Manual of Meat Inspection Procedures of the USA"), e com a técnica sugerida por Arundel (1972) em realizar incisões nos músculos mastigatórios internos e externos.

Deve-se enfatizar que nove dos cisticercos $(64,3 \%$ dos detectados nos músculos mastigatórios) encontrados, neste estudo, só foram visualizados após o segundo corte praticado nos músculos masseteres e pterigóideos, mostrando a importância de se executar de forma sistemática o segundo corte na rotina de inspeção post mortem de cabeças bovinas, em ambos os locais.

A percentagem de cisticercos encontrada no exame do coração $(1,63 \%)$ neste estudo, utilizando técnica descrita por Santos (1976), também difere dos dados recentes apresentados por Fonseca et al. (2001) que realizaram pesquisa de cisticercos no coração de bovinos, conforme preconiza o Riispoa (1952) artigo 176 parágrafo $5^{\circ}$ do Ministério da Agricultura, tendo eles encontrado a prevalência de $0,36 \%$. Além de superar a prevalência de $1 \%$, em coração bovino, obtida por (Santos, 1976), e ficar abaixo da obtida por Santos (1993) que registrou a prevalência de $2,36 \%$ de cisticercos em exame do coração bovino. Esta última prevalência pode ter superado a encontrada no presente estudo, pelo número de animais (1211 vezes maior) utilizado por (Santos, 1993) ou pelas diferentes regiōes onde foram realizados os estudos.

A prevalência $(3,16 \%)$ de cisticercose bovina, detectada por Santos (1987) utilizando nova técnica de exame do diafragma, e a prevalência de $1,83 \%$ relacionada a animais monocisticercósicos, detectados no diafragma por Santos (1984), supera a prevalência de $0,46 \%$ obtida neste estudo.

Segundo Fukuda (1996), com dados obtidos pelo Serviço de Inspeção Federal do Eștado de São Paulo, para estabeleci- 
mentos que não realizavam o exame do diafragma, foi encontrada prevalência de $0,07 \%$, contra $0,57 \%$ nos estabelecimentos onde se realizava o exame. Esta última prevalência está um pouco acima da encontrada neste estudo, em relação ao exame do diafragma, apesar da técnica empregada neste trabalho facilitar melhor a visualização dos cisticercos, já que retira a pleura parietal e o peritônio, evidenciando somente a porção muscular, ao contrário dos exames normalmente realizados no diafragma preso à carcaça bovina.

Os dados obtidos neste trabalho são concordantes com os de Teixeira (1996) que cita como locais de predileção dos cisticercos os músculos mastigatórios, coração, e língua, sendo que as prevalências de cisticercos obtidas pelo autor, foi maior no coração $(3,03 \%)$ que nos músculos mastigatórios $(1,21 \%)$.

Mitchell (1967) também detectou mais cisticercos no coração (20\%) que nos músculos da mastigação (18,86\%), assim como Santos (1993) que registrou prevalência média no coração de $62,44 \%$ e nos músculos mastigatórios $30,30 \%$. Esses dados diferem dos obtidos neste estudo: $56 \%$ nos músculos mastigatórios contra $28 \%$ no coração, em relação ao número de animais infectados.

Fernandez e Rezende (2001) verificaram que a ocorrência de cisticercose foi em $21,67 \%$ das carcaças inspecionadas, sendo encontrados nos músculos mastigatórios (20\%), coração $(6,67 \%)$, esôfago $(1,67 \%)$, língua $(1,67 \%)$ e diafragma $(1,67 \%)$. Estas prevalências são semelhantes àquelas obtidas neste estudo, considerando os locais de predileção: músculos mastigatórios, coração, língua e diafragma; porém distintos pelas prevalências superiores em porcentagens por local de predileção. Tal fato pode ter ocorrido por se tratar de animais clandestinos, sendo normalmente descartes de má qualidade, o que inviabilizaria o abate em matadouro pelo "risco de condenação", ou talvez pelo contato estreito dos animais com o homem, já que quase a metade dos animais eram fêmeas leiteiras, ou pelo número reduzido de animais (60) utilizados no estudo.

$\mathrm{Na}$ Tabela 2, observa-se o número de cisticercos morfologicamente íntegros e de cisticercos degenerados por locais de predileção. Nos músculos mastigatórios foram detectados cinco cisticercos morfologicamente íntegros $(1,16 \%)$ e nove degenerados $(2,10 \%)$. No coração, foram detectados: um $(0,23 \%)$ cisticerco morfologicamente íntegro e seis cisticercos degenerados $(1,40 \%)$. $E$, tanto na língua quanto no diafragma, foram encontrados dois cisticercos degenerados, com prevalência de $0,46 \%$ para cada local.

Tabela 2 - Presença de cisticercos de acordo com os locais de predileção nos bovinos abatidos.

\begin{tabular}{c|cccc}
\hline & \multicolumn{5}{|c}{ Cisticercos } \\
$\begin{array}{c}\text { Locais de } \\
\text { predileção }\end{array}$ & $\begin{array}{c}\text { morfologicamente } \\
\text { vivos }\end{array}$ & $\%$ & degenerados & $\%$ \\
\hline $\begin{array}{c}\text { Músculos } \\
\text { mastigatórios }\end{array}$ & 5 & 1,16 & 9 & 2,10 \\
\hline Coração & 1 & 0,23 & 6 & 1,40 \\
\hline Língua & - & - & 2 & 0,46 \\
\hline Diafragma & - & - & 2 & 0,46 \\
\hline TOTAL & 6 & 1,39 & 19 & 4,42 \\
\hline
\end{tabular}

Os dados obtidos neste estudo mostram que a prevalência de $4,42 \%$ referente a 19 cisticercos degenerados (inviáveis), foi superior em 3,17 vezes a prevalência de 1,39\% referente a seis cisticercos morfologicamente íntegros.

Observou-se, neste estudo, que dos cisticercos detectados em 25 animais, 76\% estavam degenerados (inviáveis) e $24 \%$ estavam morfologicamente íntegros. Esses dados são iguais ao citado por Santos (1976), e próximos aos obtidos por Costa et al. (1977) $71 \%$ de cisticercos degenerados (inviáveis) e $29 \%$ de cisticercos morfologicamente íntegros e dos obtidos por Santos (1984) 78,39\% de cisticercos degenerados (inviáveis) e $21,61 \%$ de cisticercos morfologicamente íntegros. Porém, difere daqueles apresentados por Fernandez (2001), que registrou em seu trabalho a prevalência de $94,73 \%$ de cisticercos viáveis (um dado incomum em relação à maioria dos trabalhos publicados).

Ressalva-se que, apesar das prevalências de cisticercos degenerados $(76 \%)$ e de cisticercos morfologicamente íntegros (24\%) serem idênticas neste estudo e no de (Santos, 1976), este último autor obteve dados utilizando, apenas, nova técnica de inspeção de coração bovino, ao contrário do presente trabalho, que realizou mais de uma técnica padronizada.

$\mathrm{Na}$ Tabela 3, observa-se as respectivas datas de abate, procedência dos bovinos por município, sexo e idade dos animais, localização e estádio dos cisticercos.

Observa-se que $67 \%$ dos cisticercos morfologicamente integros (quatro dos seis detectados) ocorreram nos animais mais velhos inspecionados neste estudo, concordando com Pugh e Chambers (1989), que encontraram uma prevalência maior de cisticercos morfologicamente íntegros em bovinos velhos e cisticercos degenerados (inviáveis) em animais jovens. A relação entre o número de cisticercos degenerados e cisticercos morfologicamente íntegros, demonstra que no coração encontra-se seis vezes mais cisticercos degenerados (6) que morfologicamente íntegros (1), enquanto que na cabeça essa relação diminui para 1,8 (5 morfologicamente íntegros para 9 degenerados). Esses dados obtidos no coração e transformados em porcentagem $(85,71 \%$ de cisticercos degenerados e $14,29 \%$ de morfologicamente íntegros), são semelhantes aos de Santos et al. (2001) que constataram a predominância dos cisticercos mortos $(83,45 \%)$ sobre os morfologicamente íntegros $(16,6 \%)$ em inspeção de corações bovinos.

A maioria dos animais (96\%) apresentou apenas um cisticerco, porém um bovino procedente de Conceição de Macabu, RJ, macho, de aproximadamente quatro anos, apresentou dois cisticercos morfologicamente íntegros no coração. Obtiveramse, dessa forma, dados semelhantes aos de (Santos, 1984) sobre o número de animais monocisticercósicos (96\%) e animais pluricisticercósicos (4\%).

Observa-se na Figura 1 os dados sobre cisticercose bovina obtidos na Coordenadoria de Controle de Qualidade de Produtos Agropecuários Industrializados, da Secretaria de Agricultura, Abastecimento, Pesca e Desenvolvimento do Interior do Estado do Rio de Janeiro, em relação à percentagem de cisticercos encontrados no matadouro de Três Rios (onde foi realizado parte do estudo): $1,1 \%$ em maio/1999, 0,23\% em junho/1999, e os dados encontrados neste estudo, no mesmo matadouro: 4,37\% em maio/2001; 7,11\% em junho/2001. 
Tabela 3 - Procedência dos bovinos abatidos e inspecionados, de acordo com sua origem

\begin{tabular}{|c|c|c|c|c|c|}
\hline $\begin{array}{l}\text { DATA DO } \\
\text { ABATE }\end{array}$ & MUNICÍPIO & SEXO & $\begin{array}{l}\text { IDADE EM } \\
\text { ANOS }\end{array}$ & $\begin{array}{l}\text { LOCALIZAÇÃO } \\
\text { CISTICERCO }\end{array}$ & $\begin{array}{l}\text { ESTÁDIO DOS } \\
\text { CISTICERCOS }\end{array}$ \\
\hline \multirow{7}{*}{$12 / 5 / 2001$} & Carmo & Macho & 3 & Cabeça & Degenerado \\
\hline & Itaperuna & Macho & 3 & Língua & Degenerado \\
\hline & Itaperuna & Fêmea & 4 & Cabeça & Degenerado \\
\hline & Petrópolis & Macho & 3 & Cabeça & Vivo \\
\hline & Três Rios & Macho & 3 & Cabeça & Degenerado \\
\hline & Três Rios & Macho & +4 & Cabeça & Vivo \\
\hline & Três Rios & Macho & +4 & Coração & Degenerado \\
\hline \multirow{10}{*}{$9 / 6 / 2001$} & Três Rios & Macho & 4 & Cabeça & Vivo \\
\hline & Três Rios & Fêmea & +4 & Cabeça & Vivo \\
\hline & Três Rios & Macho & 4 & Cabeça & Degenerado \\
\hline & Três Rios & Macho & 2 & Cabeça & Degenerado \\
\hline & Três Rios & Macho & 3 & Coração & Degenerado \\
\hline & Três Rios & Fêmea & 4 & Coração & Degenerado \\
\hline & Três Rios & Macho & 3 & Diafragma & Degenerado \\
\hline & Vassouras & Macho & 3 & Coração & Degenerado \\
\hline & Vassouras & Macho & $2 \frac{1}{2}$ & Coração & Degenerado \\
\hline & Vassouras & Macho & 2 & Cabeça & Degenerado \\
\hline \multirow{6}{*}{$30 / 6 / 2001$} & Conc de Macabu & Macho & 3 & Cabeça & Vivo \\
\hline & Conc de Macabu & Macho & 4 & Coração & Vivo \\
\hline & Conc de Macabu & Macho & +4 & Diafragma & Degenerado \\
\hline & Rio Claro & Macho & 3 & Cabeça & Degenerado \\
\hline & Rio Claro & Macho & 3 & Coração & Degenerado \\
\hline & Rio Claro & Fêmea & 4 & Língua & Degenerado \\
\hline \multirow{2}{*}{$10 / 12 / 2001$} & Cantagalo & Fêmea & $2 \frac{1}{2}$ & Cabeça & Degenerado \\
\hline & Macuco & Macho & +3 & Cabeça & Degenerado \\
\hline
\end{tabular}

Calculando-se as prevalências médias, com os dados demonstrados na Figura 1 observa-se que as técnicas padronizadas, utilizadas neste estudo, aumentaram o valor da detecção da cisticercose em 8,63 vezes em relação aos dados do SIE-RJ.

Verificou-se, também, que a média da prevalência obtida pelo SIE, no matadouro de Três Rios, RJ, foi de 0,665 e a média da prevalência com as técnicas padronizadas, no mesmo matadouro, de 5,74. Assim, a eficiência das técnicas padronizadas em relação aos dados obtidos pelo SIE Três Rios, RJ, calculada sobre as respectivas prevalências, foi de $763,16$.

\section{Conclusões}

1) Com a adoção das técnicas padronizadas obteve-se a eficiência de $763,16 \%$ sobre os dados registrados pelo Serviço de Inspeção do Estado do Rio de Janeiro.

2) A prevalência da cisticercose bovina nos matadouros do Estado do Rio de Janeiro estudados foi de 5,81\% utilizando-se técnicas padronizadas de inspeção post mortem, mostrando-se bastante superior aos dados publicados no Estado.

3) Os locais de predileção dos cisticercos foram principalmente os músculos mastigatórios $(56 \%)$ e o coração $(28 \%)$, seguido da língua e diafragma (ambos com $8 \%$ cada).

4) Foram encontrados 3,17 vezes mais cisticercos inviáveis (19) que cisticercos morfologicamente íntegros (6).

5) A prevalência de animais monocisticercósicos (96\%) predominou sobre a de animais pluricisticercósicos (4\%).

6) A utilização da técnica padronizada melhorou a deteç̧ão de casos de cisticercose e os resultados deste trabalho poderão servir de orientação e oferecer subsídios para o Serviço de Inspeção Estadual no tocante a detecção de $C$. bovis em matadouros.
Figura 1 - Comparação entre as prevalências de $C$. bovis obtidas pelos dados do SIE (Serviço de Inspeção Estadual) - RJ com aquelas obtidas com a técnica padronizada de inspeção post mortem utilizada neste estudo 


\section{Referências}

ARUNDEL, J.H. A review of cysticercosis of sheep and cattle in Austrália. Australian Veterinary Journal, Brisbane, v. 48, n. 4, p. 140-155, 1972.

BOLETIM TÉCNICO CAROL. Cuidado com a cisticercose bovina. 7ed., p. 6, outubro de 2001. [On Line] Available: http://www.carol.com.br/ estilo/boletim.asp?edi=7\&pag=6.

BRASIL. RIISPOA (Regulamento da Inspeção Industrial e Sanitária de Produtos de Origem Animal), aprovado pelo Decreto n 30.691, de 293-52, alterado pelos Decretos nos 1.255 de 25-6-62, 1.236 de 2-9-94, no 1.812 de 8-2-96 e no 2.244, de 04-06-97. 1952, 241 p.

BUSETTI, E. T.; GIOVANNONI, M.; FRANÇA, D.C.; COSTA, M.L. Cisticercose e hidatidose em bovinos (1967-1971). Arq. Biol. Tecnol., v. 19, p. 31-42, 1976.

CALIL, R. M. Situação atual do complexo teníase humana-cisticercose no Brasil. Comun. Cient. Fac. Med. Vet. Zoot. USP, São Paulo, v. 8, n. 2, p. 227-229, 1984.

COSTA, A. J.; SOBRINHO, A.M.; ÁVILA, F.A.; SOBRINHO, E.C. Distribuição geográfica da freqüência de cisticercose bovina em algumas regiões do Estado de São Paulo - Brasil. Científica, Jaboticabal, v. 5, n. 3, p. 370-379, 1977.

DRABBLE, J. Textbook of meat inspection. 10. ed. Angus \& Robertson, p. 364-365, 1969.

FERNANDEZ, A. T.; REZENDE, R. C. Ocorrência de cisticercose em bovinos abatidos clandestinamente no município de Silva Jardim - RJ. [On Line] Available: http://www.crmvrj.com.br/lVcong/lvcong.htm, 2001. FONSECA, M. A.; DUARTE, L. S.; AMORIM, M.; SERRA-FREIRE, N. M. Cisticercose bovina em animais inspecionados em matadouro frigorífico, no município de Três Rios, Rio de Janeiro. [On Line] Available: http:// www.crmvrj.com.br/IVcong/lvcong.htm, 2001.

FRANCIS, M. et al. Cisticercose bovina, suína e humana e suas relações com as teníases humanas. Atas Soc. Biol. Rio Janeiro, Rio de Janeiro, v. 20, p. 1-6, 1979.

FUKUDA, R. T.; SANTOS, I. F.; ANDRADE, C. R. Estudo comparativo entre técnicas de inspeção do diafragma para o diagnóstico da Cisticercose bovina. Higiene Alimentar, São Paulo, v. 12, n. 55, p. 51 62, 1998.

JORDÃO, E. Causas de apreensão e destino de carcaças de boi com diferentes idades abatidos em matadouros do Estado de São Paulo. Higiene Alimentar, São Paulo, v. 3, n. 1, p. 44-58, 1984.

KOUDELA, K. Organen-lokalisation von Cysticercus bovis beischwach invadierten riden. Helminthologia, v. 7, p. 235-243, 1966.

Mc COLL, C. J. Distribuition of Cysticercus bovis in lightly infected young cattle. Aust. Vet. J., v. 5, p. 214-221, 1979.

MITCHELL, J. R. Incidence and predilection sites of Cysticercus bovis (inermis) in cattle in Uganda. Die Fleischwirschaft. v. 47, p. 977-979, 1967.

MOREIRA, M. D. Caracterização da cisticercose de bovinos abatidos em matadouros municipais de Divinópolis e Uberlândia, MG, Brasil. Tese apresentada para obtenção de título de mestre em Medicina Veterinária, UFMG. Veterinária Notícia. v. 6, n. 2, 2000. [On Line] Available: http://www.famev.ufu.br/vetnot/vetnot6/res6-2-20.html.
OLIVEIRA, P. R.; SILVA, P.L.; RIBEIRO, S.C.A.;REIS, D.O. Prevalência da cisticercose em carcaças e vísceras de bovinos abatidos em Uberlândia. Arq. Bras. Med. Vet. Zoot., Uberlândia, v. 36, n. 4, p. 443450, 1984.

PARDI, M. C.; DUARTE, G. C.; ROCHA, U. F. Cisticercose em bovinos e suínos (Análise estatística de dados colhidos pelo SIFn², do DIPOA, do Ministério da Agricultura, junto ao frigorífico Anglo de Barretos, Estado de São Paulo, Brasil). Revista da Faculdade de Medicina Veterinária, São Paulo, v. 4, p. 613-628, 1952.

PUGH, K. E.; CHAMBERS, P. G. Observations on Cysticercus bovis in slaughter cattle in the Matabeleland Province of Zimbabwe. Veterinary - Record, v. 125, n. 19, p. 480-484, 1989.

RODRIGUES, L. V. C. Inspeção sanitária e critérios de julgamento da cisticercose bovina calcificada - infecção leve. Tese (mestrado em Higiene Veterinária e Processamento Tecnológico de Produtos de Origem Animal), Faculdade de Veterinária, Universidade Federal Fluminense, 1992.

SANTOS, I. F. Nova técnica de exame do coração na rotina de inspeção da cisticercose bovina. Tese (mestrado em Ciência, Higiene e Tecnologia de Alimentos), Faculdade de Veterinária, Universidade Federal Fluminense, 1976

SANTOS, I. F. Diagnóstico dä cisticercose bovina em matadouros: novas técnicas de exame de esôfago e diafragma. Tese (doutorado em Saúde Pública), Universidade de São Paulo, São Paulo, 127 p. 1984.

SANTOS, I. F. Diagnóstico da cisticercose bovina em matadouros. Exame do diafragma. Arq. Flum. Med. Vet, Niterói, v. 2, n. 3, p. 72-78, 1987.

SANTOS, I. F. Um modelo de inspeção para a detecção da cisticercose muscular bovina em matadouros. Tese (Concurso para Professor Titular) - Departamento de Tecnologia de Alimentos, Universidade Federal Fluminense, Niterói, 1993, $73 \mathrm{p}$

SANTOS, I. F. Diagnóstico da cisticercose bovina em matadouros. Exame dos pilares diafragmáticos. Higiene Alimentar, São Paulo, v. 7, n. 25, 1993a.

SANTOS, I. F.; MANO, S. B.; TORTELLY, R.; SANTOS, M. L. S.; SILVA, D. A. S. Estudo da localização do Cysticercus bovis em corações de bovinos abatidos sob inspeção. Higiene Alimentar, São Paulo, v. 15, n. 89 , p. 37-44, 2001.

SILVA, O. C. Fiscalização sanitária de carnes no matadouro de Santa Cruz. In: CONGRESSO BRASILEIRO DE VETERINÁRIA, 2. Rio de janeiro, 1943.

TEIXEIRA, A. L. de S. Distribuição geográfica da freqüência da cisticercose em bovinos abatidos em estabelecimento sob inspeção federal no Estado do Rio de Janeiro. Niterói, 1996. 69 p. Monografia apresentada à Universidade Federal Fluminense para obtenção do grau de médico-veterinário, 1996.

UNGAR, M.L. Prevalência da cisticercose bovina do Estado de São Paulo, detectada em matadouros do referido estado, sob o controle do Serviço de Inspeção Federal, no ano de 1986. São Paulo, 1990. 120 p. Tese (Mestrado em epidemiologia), Faculdade de Medicina Veterinária e Zootecnia, Universidade de São Paulo, 1990. 